\title{
El inconcluso régimen legal de las mutuas de seguros y la paulatina desmutualización del sector asegurador español ${ }^{1}$
}

\author{
Carlos Vargas Vasserot \\ Catedrático de Derecho Mercantil \\ Universidad de Almería
}

Sumario: 1. Mutualidad, seguro y mutuas de seguros. 2. La evolución legislativa de las mutuas de seguros y su incompleto marco legal en la actualidad. 3. Naturaleza jurídica de las relaciones mutualistas en las mutuas de seguros. 4. Principales novedades del régimen legal de las mutuas y el riesgo de desmutualización del sector. a. Continuidad con el régimen anterior. b. La proscripción legal de las mutuas a prima variable. c. El régimen de modificaciones estructurales. d. Grupos mutuales. 5. Bibliografía.

Resumen: Las mutuas de seguros constituyen una forma especial de explotar la actividad aseguradora caracterizada por su naturaleza eminentemente mutualista frente a las entidades aseguradoras con forma de sociedades anónimas en las que predomina el interés lucrativo de la entidad. Sin embargo, paulatinamente se han ido equiparando las exigencias económicas y financieras, la solvencia y las bases técnicas que deben tener las mutuas y las compañías de seguros para ser autorizadas para operar en los distintos ramos, con lo que estructuralmente las diferencias entre estos dos tipos de aseguradoras no son tan evidentes y no suelen ser percibidas por los propios tomadores de seguros. Un claro impulso a este proceso de asimilación ha venido de la mano de la Ley 20/2015 de Ordenación, Supervisión y Solvencia de las Entidades Aseguradoras y Reaseguradoras y su Reglamento de desarrollo, aprobado por el Real Decreto 1060/2015. No obstante, ambos cuerpos normativos dedican escasos preceptos a las mutuas de seguros en comparación con la normativa anterior, que se mantiene básicamente en vigor hasta que se acometa una futura regulación específica de las mutuas. En el presente estudio se expondrá el origen y evolución de explotación del seguro a través de mutuas, la naturaleza jurídica de las relaciones mutualistas entre los asegurados y las mutuas y las principa-

1 Estudio realizado en el marco de Proyecto de Investigación DER2013-48864-C21-P del Ministerio de Economía, Industria y Competitividad del Gobierno de España, titulado «Integración cooperativa y reestructuraciones socialmente responsables. Mecanismos de creación de empleo e incremento de productividad empresarial». 
les novedades del vigente, e inacabado régimen legal de las mutuas de seguros, que se pueden resumir en tres: prohibición de las mutuas a prima variable, cambios en el régimen de modificaciones estructurales en las que participe una mutua y el reconocimiento de la posibilidad de constituir grupos mutuales basados en vínculos no de capital.

Palabras clave: mutuas de seguros, marco legal, grupos mutuales, modificaciones estructurales, relaciones mutualistas

Abstract: Insurance mutual societies constitute a special way of exploiting the insurance activity characterized by its eminently mutualistic nature in opposition to the insurers with the form of corporations in which the lucrative interest of the entity predominates. However, the economic and financial requirements, the solvency and the technical bases that mutual societies and insurance companies must have to be authorized to operate in the different sectors have gradually been equated, so the differences between these two types of insurers are not so obvious and are not usually perceived by the policy holders themselves. A clear impulse to this process of assimilation has come from the Act 20/2015 of Ordinance, Supervision and Solvency of Insurance and Reinsurance Entities and its development Regulation, approved by Royal Decree 1060/2015. However, both regulatory bodies devote scarce precepts to mutual insurance societies in comparison with the previous regulations, which remain basically in force until a future specific regulation of mutuals is performed. The present study will discuss the origin and evolution of insurance operations through mutual societies, the legal nature of mutual relations between insureds and mutuals, and the main novelties of the current legislation, and the unfinished legal regime of insurance mutual societies, which can be summarized as three: prohibition of variable rate mutuals, changes in the regime of structural modifications in which a mutual participates, and recognition of the possibility of forming mutual groups based on non-capital bonds.

Keywords: Insurance mutual societies, legal framework, mutual groups, structural modifications, mutual relations 


\section{Mutualidad, seguro y mutuas de seguros}

Las mutuas de seguros constituyen una forma especial de explotar la actividad aseguradora caracterizada, como otros tipos de empresas del sector que se integran en la denominada economía social — mutuas de previsión social y cooperativas de seguros - por su naturaleza eminentemente mutualista frente a las entidades aseguradoras con forma de sociedades anónimas en las que predomina el interés lucrativo de la entidad. Pero conviene, con carácter previo, hacer una serie de precisiones a esta afirmación. Mutualidad significa ayuda y socorro mutuo, satisfacción de necesidades comunes y ausencia de ánimo de lucro en la gestión con los socios², pero lo que ocurre es que la propia esencia del seguro, cualquiera que sea su forma de explotación, es siempre la mutualidad en el sentido de la existencia de un grupo de personas sometidas a los mismos riesgos que contribuyen recíprocamente a reparar las consecuencias de los siniestros que afectan a cada una de ellas ${ }^{3}$. Y lo cierto, es que como demuestra su origen y desarrollo histórico, el seguro es una institución de previsión basada en la mutualidad técnicamente organizada.

El seguro aunque encuentra sus antecedentes en diversas asociaciones de asistencia recíproca y socorro mutuo de la Antigüedad (como las que recogen el Código de Hammurabi en Oriente y las Leyes de Rodas en Grecia o las que se desarrollan en Roma a través de los collegia de enterramientos militares y civiles), surge en el ámbito del comercio marítimo en el medievo italiano, como una desviación del préstamo a la gruesa, motivada por las prohibiciones canónicas que calificaban a éste de usurario por los intereses cobrados (usurae maritimae), que eran notablemente superiores a los normales y sin limitaciones ${ }^{4}$. Pos-

2 En nuestra doctrina los dos trabajos esenciales sobre la mutualidad, aunque referida esencialmente a las sociedades cooperativas, son Llobregat HURTADO, Mutualidad y empresas cooperativas, Barcelona, Bosch, 1991 y PANIAGUA Zurera, Mutualidad y lucro en la sociedad cooperativa, MacGraw-Hill, Madrid, 1997.

3 Por todos, Garrigues, en su magistral Contrato de seguro terrestre, Madrid, 1. a ed., 1973, pp. 23-34.

4 Para eludir las terminantes proscripciones eclesiásticas sobre la usura, se intentó dar al contrato de préstamo a la gruesa una apariencia de licitud que finalmente desembocó en una nueva institución: el contrato de seguro marítimo, que vino a sustituir a la cobertura de los riesgos propios de la expedición marítima que se realizaba por el préstamo a la gruesa; y la prima del seguro, precio de dicha cobertura, a los intereses remuneratorios. Sobre la descripción del desarrollo del seguro marítimo a partir de la prohibición del préstamo a la gruesa por usurario, y las diversas justificaciones de la naturaleza jurídica del seguro vid. la clásica obra de GoLDSCHMIDT, Storia universale del diritto commerciale (trad. Pouchain y Scialoja de la original Universalgeschichte des Handelsrechts, Stuttgart, 1891), Torino, 1913, pp. 281 a 283. 
teriormente, como se sabe, la práctica del seguro se extiende a actividades diferentes de la navegación y del propio comercio y el ámbito de los bienes e intereses asegurables y de los sujetos que intervienen como tomadores del seguro o como asegurados, pero desde momentos muy iniciales de la institución se pueden distinguir dos formas de explotación del seguro: la mutua y la lucrativa.

La primera parece que surge históricamente en el siglo XIII en Alemania y en Flandes como un desarrollo del auxilio mutuo que daban las guildas medievales (corporaciones de mercaderes o comerciantes también denominadas hansas) en caso de siniestros sufridos por sus miembros, en especial contra incendios (Brandgilden). Se cita un seguro concertado en forma mutua en 1591 por cien fabricantes de cerveza de Hamburgo como el contrato de seguros de incendios más antiguo del que se tiene constancia documental ${ }^{5}$

Estas primitivas asociaciones de asistencia recíproca por su defectuosa organización técnica y limitado ámbito de actuación generaban evidentes riesgos para sus asociados, por lo que fueron paulatinamente siendo sustituidas a partir del siglo XVIII por entidades públicas de seguros (Sozietäten) hasta llegar a la fundación de grandes mutuas de seguros a principios del siglo XIX $X^{6}$. En España el proceso fue parecido, pero el germen de las mutuas de seguros se encuentra en las cofradías y posteriores hermandades de socorro de los gremios muy influenciados por la iglesia (siglo XIV) que pasaron después (siglo XVIII) a ser sustituidas por los montepíos ya bajo el control del Estado 7 . En cualquier caso, es un hecho que el mutualismo de previsión y socorro mutuo nació antes que el mutualismo estrictamente de seguros ${ }^{8}$. Sin embargo, en España la primera Compañía de seguros se creó en 1785 en el ámbito marítimo, mientras que la primera mutua de seguros de la que se tiene constancia es la Sociedad de Seguros Mutuos de Incendios de casas en Madrid que se constituyó en $1822^{9}$.

Este tipo de entidades se caracterizan aún hoy porque la masa social y la masa de asegurados coinciden y recordemos que el seguro es

5 Benítez de Lugo, Tratado de seguros, vol. I, Madrid, 1955, p. 100.

6 Herrmannsdorfer, Seguros Privados, Madrid, 1933, pp. 30 y s.

7 Ávalos, «Antecedentes históricos del mutualismo», CIRIEC-España, núm. 12, pp. 40-42.

8 MoReNo, «La génesis del mutualismo moderno en Europa», REVESCO, núm. 72, pp. 199-214.

9 Por seguir con las curiosidades históricas, en 1834 se funda la Mutua de Extramuros en Madrid y la Mutua de Sevilla, y en 1835 se constituye la Sociedad de Seguros Mutuos contra incendios de Barcelona. Datos extraídos de GARRIDO Y COMAS, Tratado general de seguros, t, I, vol. I, Madrid, 1986, pp. 26 y s. 
un contrato de masas y valga la redundancia. Los asegurados se convierten en mutualistas con la conclusión del contrato de seguro y, en teoría, gestionan directamente los intereses colectivos de cobertura de riesgos comunes y propios. En cambio, en la explotación lucrativa del seguro, los socios (accionistas) y la propia entidad (sociedad anónima) tienen como principal interés obtener ganancias por la cobertura de riesgos ajenos, los de sus clientes. Esta distinta finalidad perseguida en la explotación del seguro ha tenido un natural reflejo en la manera de funcionar de estas dos formas de aseguramiento. Lo que ocurre es que, si como ya señalaba el profesor GARRIGUES a principio de los años setenta del siglo pasado, la distinción entre ambas formas de explotación en teoría era fácil y en la práctica difícili10, en la actualidad en muchas ocasiones son inapreciables los rasgos diferenciales de ambas clases de aseguradoras, incluso para los propios asegurados que muchas veces no saben la naturaleza jurídica que tiene la entidad que asegura sus riesgos.

Desde hace mucho tiempo el papel contractual de asegurador se encuentra monopolizado, tanto por razones técnico-económicas como estrictamente legales, por unas empresas mercantiles que son los diferentes tipos de entidades aseguradoras no admitiéndose ni el seguro entre particulares ${ }^{11}$ y ni siquiera el seguro concertado por una entidad que no haya sido autorizada por la autoridad administrativa correspondiente que es declarado nulo de pleno derecho. Así, el contrato o la relación de seguro siempre contrapone al menos a dos sujetos: por un lado, una empresa especializada en el aseguramiento de riesgos y por otra un sujeto, que en la mayor parte de los casos es un simple consumidor o bien un profesional o empresario que no está especializado en el ámbito del seguro. No obsta a esta afirmación el hecho de que el fenómeno mutualístico (es decir, el autoaseguramiento por los propios interesados eludiendo la intervención de un empresario de finalidad lucrativa) haya tenido una singular importancia en este sector económico, porque, en cualquier caso, ya se trate de una organización que responda a una idea capitalista o a una idea mutualista, lo que está claro es que la actividad aseguradora, por su extraordinaria comple-

10 Contrato de seguro terrestre, cit., p. 28.

11 Recordemos que el régimen del contrato de seguro del Código civil (arts. 1791 1797) fue expresamente derogado por la disposición final de la Ley 50/1980 del Contrato de Seguro. En dicha regulación, tras regular el seguro contratado entre dos sujetos (art. 1791), admitía que "también puede asegurarse mutuamente dos o más propietarios del daño fortuito que sobreventa en sus bienes respectivos» (art. 1792). 
jidad técnica y por la acumulación de fondos necesaria para desarroIlarla, sólo se permite explotarlas por empresarios sociales de cierta entidad y que cumplan una serie de requisitos. Por ello, a las mutuas con el tiempo se les ha ido dotando de una estructura corporativa y de una organización similar a las de las sociedades anónimas de seguros y se han sometido a un control y supervisión cada vez más parecido al del resto de entidades del sector. De este modo, paulatinamente se han equiparando las exigencias económicas y financieras, la solvencia y las bases técnicas que deben tener las mutuas y las compañías de seguros para ser autorizadas para operar en los distintos ramos, con lo que estructuralmente las diferencias entre estos dos tipos de aseguradoras no son tan evidentes.

Un claro ejemplo de este proceso de asimilación iniciado en España desde hace décadas por la normativa de ordenación y supervisión de los seguros privados, exigiendo que las mutuas de seguros acrediten un fondo mutual permanente en cuantía semejante al capital social de las sociedades anónimas de seguros. En esta línea la reciente incorporación a nuestro ordenamiento de la «Directiva 2009/138/CE del Parlamento Europeo y del Consejo sobre el seguro de vida, el acceso a la actividad de seguro y de reaseguro y su ejercicio» (Solvencia II), fundamentalmente a través de la Ley 20/2015 de Ordenación, Supervisión y Solvencia de las Entidades Aseguradoras y Reaseguradoras (se cita LOSSEAR) y su Reglamento de desarrollo, aprobado por el Real Decreto 1060/2015 (se cita ROSSEAR), va a obligar a las mutuas de seguros a establecer y documentar un modelo de gestión integral de riesgos, mayores requerimientos de recursos propios y de márgenes de solvencia, un incremento de la transparencia, mejora de la información y refuerzo de los mecanismos de tutela de los tomadores, con implicaciones en la propia gobernanza de estas entidades. Y mucho me temo que algunas, las de menor dimensión, no serán capaces de adaptarse a estas exigencias y serán absorbidas por otras mutuas o se transformarán en compañías de seguros.

Y esta paulatina aproximación estructural, organizativa y de funcionamiento financiero y técnico ha ido acompañada de una paulatina asimilación jurídica de ambos tipos de entidades. De este modo, el histórico divorcio entre el Derecho mercantil y las entidades mutualistas, consagrado en el artículo 124 del Código de Comercio de 1884, aún formalmente vigente, que las consideraba sólo mercantiles si se dedicaban a operar con terceros no socios o se convertían en sociedades a prima fija, lo que según nuestro ordenamiento estaba prohibido al ser ambas circunstancias incompatibles al concepto de mutua, ha ido su- 
perándose ${ }^{12}$. Primero, desde posiciones doctrinales que defendían que las mutuas eran sociedades mercantiles aún sin tener ánimo de lucro y, después, con la intervención del legislador que ha terminado por calificarlas expresamente como tales.

No es el momento de entrar en la discusión doctrinal sobre la naturaleza jurídica de las mutuas dado, además de que la Ley deja claro su carácter de sociedad mercantil en nuestro ordenamiento ${ }^{13}$. No obstante, cabe recordar que si bien durante el siglo XIX y mitad del XX la tesis mayoritaria era la consideración de las mutuas de seguros como asociaciones al hilo de su reconocimiento como tales en la Ley de Asociaciones de $1887^{14}$ y en las leyes de ordenación del seguro privado de la época (1908 y 1954), hoy esta tesis está totalmente superada, como la que consideraba que eran sociedades civiles $^{15}$. El camino a la mercantilización de las mutuas lo aclaró el legislador con la Ley 33/1984 sobre Ordenación del Seguro Privado que parte de su calificación como sociedades mutuas y distinguía las que operaban a prima fija y las que

12 Art. 124 C.com.: «Las compañías mutuas de seguros contra incendios, de combinaciones tontinas sobre la vida para auxilio a la vejez, y de cualquiera otra clase [...], sólo se considerarán mercantiles, y quedarán sujetas a las disposiciones de este Código, cuando se dedicaren a actos de comercio extraños a la mutualidad o se convirtieren en sociedades a prima fija». La Exposición de Motivos del Código argumentaba que no se consideran sociedades mercantiles a las asociaciones mutuas «porque falta en ella el espíritu de especulación que es incompatible con estas sociedades».

13 Para lo que remito a CARRo DEL CASTILLO, «Naturaleza jurídica de las mutuas de seguros», en Comentarios a la Ley de Ordenación del Seguro Privado, Dir. Verdera, vol. I, Madrid, 1988, pp. 423-443.

14 El artículo 1, 2. ${ }^{\circ}$ de Ley de Asociaciones de 1887 expresamente reconocía que se regían por dicha norma las sociedades de socorros mutuos y de previsión (art. 1, 2. ${ }^{\circ}$ ). Mientras que la Ley de Asociaciones de 1964 era menos clara al respecto, la Ley 1/2002 de Asociaciones excluye expresamente a las mutuas de su ámbito (art. 1.4).

15 La defensa de la naturaleza de sociedad mercantil de la mutua fue iniciada en nuestra doctrina por SÁnchez Calero, Curso de Derecho del Seguro Privado, Bilbao, 1961, pp. 63 y s., apoyada, esencialmente, en la forma de organización de las mutuas de seguros como empresas mercantiles junto a la imposición de bases técnicas y tarifas iguales que las de las sociedades anónimas de seguros, que las hacían operar de facto a prima fija. En contra, BERCovitz RodRíGUEZ-CANO y BROSETA PONT, «Mutuas de seguros, prima fija y carácter no mercantil», RDM, núms. 179180, 1986, pp. 7-59; y "Consideraciones sobre la naturaleza jurídica de las mutuas de seguros», RES, núm. 46, 1986, pp. 173-186; y VICENT CHULIÁ, "Las empresas mutualísticas y el Derecho mercantil en el ordenamiento español», RCDI, núm. 512, 1976, pp. 69-134 y "Aspectos relevantes del régimen jurídico de la mutua de seguros a prima fija», $R G D$, núms. 640-641, 1998, pp. 615-650, que con parecidos argumentos consideraban que las mutuas necesariamente, por la posibilidad de derramas activas y pasivas, trabajan a siempre a prima variable y, por tanto, no son mercantiles. 
lo hacían a prima variable (arts. 13 y 14), sometiendo a las primera a similares exigencias de constitución y publicidad que a las sociedades mercantiles con la obligación de inscribirse en el Registro Mercantil (art. 12.316). Por su parte, el Reglamento de Ordenación del Seguro Privado de esa Ley (RD 1348/1985) reguló los órganos sociales teniendo como referencia el régimen legal de las sociedades anónimas (arts. 29-35).

La Ley 30/1995 de Ordenación y Supervisión del Seguro Privado (se cita LOSSP) contiene un régimen sobre las mutuas de seguros similar a la Ley precedente pero ya no habla de sociedades mutuas y se refiere a ellas como entidades privadas sin ánimo de lucro. En cambio, sigue avanzando en la asimilación de las mutuas a prima fija con las sociedades mercantiles el Reglamento de Ordenación y Supervisión de los Seguros Privados (RD 2486/1998), vía derecho supletorio, al declarar que en todo lo no previsto en la normativa y en los estatutos es de aplicación supletoria el régimen legal de las sociedades anónimas [art. 9.4, letra c) ${ }^{17}$. Y si esta aplicación supletoria del Derecho de sociedades anónimas la juntamos con que la regulación legal especial para estas entidades es poco extensa, de nuevo vemos como las diferencias jurídicas entre mutuas y sociedades anónimas de seguros son menores que las que, en principio pudieran parecer. Finalmente, la LOSSEAR ha reconocido ya abiertamente a las mutuas como sociedades mercantiles (art. 41.1).

Por otra parte, el sistema de cobertura de riesgos también históricamente ha sido diferentes entre ambas formas de explotar el seguro en relación con los pagos que deben hacer los asegurados, o mejor dicho, los tomadores del seguro, para estar cubiertos por el seguro ${ }^{18}$. En las sociedades anónimas se ha utilizado siempre el sistema de primas, es decir, el tomador paga un precio fijado anticipadamente por la cobertura del el seguro y la compañía queda obligada a cumplir con las condiciones estipuladas en la póliza del seguro. El riesgo del seguro, en el sentido de riego de la empresa, corre a cargo de la entidad aseguradora, que puede obtener beneficios si los ingresos por primas han

16 Art. 16.1.3. ${ }^{\circ}$ C.com.; arts. 81.1, letra c) y 254-258 RRM.

17 Como señala Paniagua Zurera, La sociedad cooperativa. Las sociedades mutuas de seguros y las mutualidades de previsión social, vol. I, tomo 12, en Tratado de Derecho mercantil, Madrid, 2005, p. 394, esto supuso una importante ampliación de la remisión a la legislación sobre sociedades anónimas que hacía el RD 1348/1985, que se refería exclusivamente a los órganos de gobierno de la mutualidad y a relaciones de los socios con la entidad (art. 36).

18 Herrmannsdorfer, op. cit., p. 22; y GARRIGUES, op. cit., pp. 24 y s. 
sido superiores a los gastos de funcionamiento de la entidad y a los pagos de indemnizaciones por siniestros realizadas $u$ obtener pérdidas en caso contrario.

En cambio, la explotación del seguro en forma mutual ha funcionado tradicionalmente por el sistema de distribución, que consiste o bien en repartir periódicamente entre todos los mutualistas las consecuencias económicas de los siniestros ocurridos a prorrata de los respectivos capitales asegurados, estableciéndose así para cada uno de ellos lo que puede llamarse una cuota a posteriori de carácter variable; o bien en calcular anticipadamente (a priori) el importe de sus obligaciones en el ejercicio venidero que se distribuye entre los mutualistas en una cantidad fija en proporción a los capitales asegurados. En este segundo caso, a la terminación del periodo si la mutua incurre en pérdidas somete a los mutualistas a una recaudación suplementaria para absorberlas (derramas pasivas) y si, por el contrario, la mutua obtiene resultados positivos se reintegra el exceso de las cuotas cobradas a los asegurados (derramas activas o retornos). Por esta diferente forma de funcionar, a las sociedades capitalistas se les ha solido exigir mayores garantías económicas que a las mutuas, ya que no cuentan con el mecanismo de poder exigir a sus clientes aportaciones personales para cubrir pérdidas.

Pues bien, de un lado, desde hace mucho tiempo se califican de primas a las cuotas que se les cobra a los mutualistas tanto por la normativa administrativa del seguro como en la práctica del sector, aunque en realidad la cantidad anticipada por el mutualista no es una prima propiamente dicha porque por el juego de las derramas activas y pasivas no es una cantidad cierta hasta que transcurre el periodo de referencia ${ }^{19}$. Por otro lado, las mutuas a prima variable que eran ya una reminiscencia histórica han sido prohibidas en nuestro ordenamiento (art. 27.1 y disp. transitoria 1. ${ }^{a}$ LOSSEAR) y, por último, por ley se establece que la responsabilidad de los mutualistas por las deudas sociales en las mutuas se limita, en todo caso, a un importe igual al de la prima que anualmente paguen [que fue una novedad de la Ley 33/1984 art. 13, 2, letra d) LOSP y que hoy sigue vigente [art. 9.2, letra d) TR-

19 Por eso, algunos autores consideran que la denominación legal de mutua a prima fija no se ajusta a la realidad del funcionamiento de las entidades a que se aplica y a que la cantidad que se anticipa de puede ver reducida por los extornos o incrementadas por las derramas pasivas: BECOVITZ y BROSETA, «Mutuas de seguros a prima fija y carácter no mercantil», cit., pp. 27 y s., y pp. 44 y s.; VICENT CHULIÁ, op. cit, pp. 28-30; TIRADO SUÁREZ, Ley ordenadora del seguro privado: exposición y crítica, Universidad de Sevilla, Sevilla, 1984, p. 72. 
LOSSP]. Además, en la práctica las diferencias de los sistemas de cobertura de riesgos de las grandes mutuas y de las sociedades anónimas de seguros son apenas reconocibles por el tomador del seguro ya que las primas se calculan mediante sofisticados programas de cálculo estadístico y de probabilidades que apenas dan lugar ni a derramas pasivas ni a retornos para los mutualistas, y de haberlas suelen ser de cantidades irrisorias.

Por tanto, la única diferencia importante que existe entre las mutuas de seguros y las sociedades anónimas de seguros es que en las primeras los asegurados son, a su vez, socios de la entidad. Este es el aspecto diferencial de la mutua de seguros respecto a las sociedades anónimas de seguro, se recoge en su concepto legal: "sociedades mercantiles sin ánimo de lucro, que tienen por objeto la cobertura a los socios, sean personas físicas o jurídicas, de los riesgos asegurados mediante una prima fija pagadera al comienzo del período del riesgo» (art. 41.1 LOSSEAR). Podemos partir entonces de un concepto de mutuas de seguros como entidades aseguradoras privadas que tienen por objeto la cobertura a sus socios de los riesgos asegurados y en las que cada socio, como tal, se encuentra en una relación contractual de seguro con la sociedad, y en las que mediante la prestación dineraria de los asociados, incluso del que es víctima del siniestro, se repara el daño sufrido con una ausencia de ánimo de lucro de los propios socios a diferencia de lo que ocurre con los de la sociedades anónimas de seguros. Como se ha defendido, es un tipo social especial por su objeto social (la actividad aseguradora), por algunas de sus características (sociedad mutualista y personalista) y por su inserción en el ámbito de la economía social ${ }^{20}$.

El concepto de economía social es difícil de concretar, ya que constituye una realidad muy diversa. Generalmente se entiende por tal, toda actividad económica de carácter privado basada en la asociación de personas en entidades de tipo democrático y participativo, con primacía de las aportaciones personales sobre las de capital y donde la distribución del beneficio y la toma de decisiones no están directamente ligadas con el capital aportado por cada socio. En España la norma de referencia en esta materia es la Ley 5/2011 de Economía Social (LES), que tiene por objeto establecer un marco jurídico común para el conjunto de entidades que integran la economía social, con pleno respeto a la normativa específica aplicable a cada una de ellas, así como determinar las medidas de fomento a fa-

20 Paniagua Zurera, op. cit., p. 403. 
vor de las mismas en consideración a los fines y principios que les son propios. La LES define a la economía social al conjunto de las actividades económicas y empresariales, que en el ámbito privado llevan a cabo aquellas entidades que, de conformidad con una serie de principios extraídos de los cooperativos, persigan bien el interés colectivo de sus integrantes, bien el interés general económico o social, o ambos $^{21}$. Pues bien, en el listado de entidades de la economía social que contiene el artículo 5.1 de la LES, se incluyen a las mutualidades junto a las cooperativas, las sociedades agrarias de transformación, las fundaciones y las asociaciones que lleven a cabo actividad económica, las sociedades laborales, las empresas de inserción, los centros especiales de empleo y las cofradías de pescadores. La consideración de las mutuas como empresas de economía social significa que se guían en su actuación por una serie de principios orientadores que se debería traducir en una sociedad participativa y democrática. Pero aunque la Ley acoja esos principios en una serie de preceptos (un socio un voto, igualdad de trato, régimen de derramas activas o retornos, derecho de información, etc.) la realidad del sector los modula y la tendencia manifiesta a constituir grandes entidades o grupos mutuales, provoca una continua aproximación funcional entre mutuas y sociedades anónimas de seguros. Y, como hemos dicho antes, gran parte de los asegurados de esas mutuas no saben que son mutualista ni qué consecuencias tiene esta circunstancia ya que realmente les interesa es el contenido contractual de esa relación asegurativa (precio de la prima, cobertura, exclusiones, etc.).

De otro lado, la gestión democrática de la mutua por parte de los socios no siempre es real. Por ejemplo, hay una limitación clara a quién puede ser elegible para ocupar cargos sociales, al exigirle el cumplimiento de una serie de requisitos, como el de cualificación o

21 Según el artículo 4 LES, los principios orientadores de la economía social son los siguientes: «a) Primacía de las personas y del fin social sobre el capital, que se concreta en gestión autónoma y transparente, democrática y participativa, que lleva a priorizar la toma de decisiones más en función de las personas y sus aportaciones de trabajo y servicios prestados a la entidad o en función del fin social, que en relación a sus aportaciones al capital social; b) Aplicación de los resultados obtenidos de la actividad económica principalmente en función del trabajo aportado y servicio o actividad realizada por las socias y socios o por sus miembros y, en su caso, al fin social objeto de la entidad; c) Promoción de la solidaridad interna y con la sociedad que favorezca el compromiso con el desarrollo local, la igualdad de oportunidades entre hombres y mujeres, la cohesión social, la inserción de personas en riesgo de exclusión social, la generación de empleo estable y de calidad, la conciliación de la vida personal, familiar y laboral y la sostenibilidad; y d) Independencia respecto a los poderes públicos». 
experiencia (art. 13.2 del Reglamento de Ordenación y Supervisión de los Seguros Privados, aprobado por el Real Decreto 2486/1998 - se cita ROSSP). Que difícilmente va a concurrir en un socio no profesional en la gestión de este tipo de empresas. Por otra parte, aunque la condición de miembro del Consejo de Administración de la mutua depende de su condición de mutualista (art. 18.2 ROSSP), es sencillo eludir esta norma puesto que con suscribir un seguro se le capacita, en este punto, para ejercer el cargo. Y así es un hecho que tanto los que se presenta a los cargos electores, como los que los eligen de manera efectiva, suelen ser minorías activas y con vínculos profesionales y/o personales con la entidad (empleados, trabajadores, cargos e incluso familiares y allegados), con lo que el ideal democrático que teóricamente rige en estas sociedades se aleja mucho de la realidad.

\section{La evolución legislativa de las mutuas de seguros y su incompleto marco legal en la actualidad}

La regulación legal de las mutuas de seguros se inicia en España con el ya comentado artículo 124 Código de comercio de 1884 que, en contra de sus antecedentes prelegislativos, determinó la inicial exclusión de las mutuas de seguros del ámbito del Derecho mercantil. Durante gran parte del siglo xx las escasas regulaciones sustantivas de las mutuas se recogieron en las leyes ordenadoras del seguro privado, siendo, con carácter general, bastante escasa la atención que se le prestaba a esta forma de explotar la actividad aseguradora.

La Ley de Seguros de 14 de mayo de 1908 que instauró en nuestro ordenamiento el control de la actividad aseguradora se aplicaba a las sociedades anónimas de seguros, a los montepíos, sociedades de socorros mutuos y a las asociaciones mutuas, pero excluía de su ámbito a aquellas mutuas «sin prima fija o cuota, de carácter local, municipal y provincial, que no tengan por fin el lucro y sí exclusivamente la indemnización de los daños o riesgos que los asociados puedan sufrir en sus bienes» (art. 3). El Reglamento de 1912 que la desarrolla, por su parte, dedica varios preceptos a las mutuas de seguros en los que reconoce las características esenciales de estas entidades (sólo se pueden asegurar a los mutualistas; no ser la operación de seguro objeto de industria o beneficio para la colectividad aseguradora; e igualdad de derechos y obligaciones de los mutualistas) y que las asociaciones puramente mutuas no podían asegurar a prima fija (arts. 29-35). Es llamativo como dicha norma evita en todo momento reconocer persona- 
lidad jurídica propia a la entidad diferente a las de sus asociados 22 y al órgano de administración lo denomina simplemente "organismo representativo y amovible emanado de la voluntad colectiva de los mutualistas» (art. 33.4). La Ley de Ordenación del Seguro Privado de 16 de diciembre de 1954 no supuso ningún cambio significativo en el planteamiento sobre las mutuas, y el contenido de su artículo 12, que establece las condiciones que debían cumplir las mutuas para ser consideradas como tales, coincide casi literalmente con el del artículo 33 del Reglamento de 1912, norma que quedo vigente hasta los años ochenta por no publicarse una específica de desarrollo de la Ley de 1954.

La Ley 33/1984 sobre Ordenación del Seguro Privado produjo un importante giro normativo en esta materia. Con anterioridad a esta norma, la regulación sobre mutuas de seguros era muy básica, con graves deficiencias técnicas y no se explicaba ni se distinguía el funcionamiento del seguro realizado por mutuas respecto al realizado por sociedades anónimas. Respecto a las novedades de la Ley de 1984, de un lado, amplió notablemente los tipos de entidades aseguradoras incluyendo de manera novedosa a las sociedades cooperativas de seguros (art. 7), que regula junto a las mutuas (capítulo III), y sometió por primera vez a las mutualidades de previsión social a las disposiciones aplicables a las entidades aseguradoras que había iniciado tiempo atrás un camino legislativo separado (especialmente con la Ley de 6 de diciembre de 1941). Por otra parte distingue con claridad el régimen de las mutuas a prima fija, esto es, que tienen por objeto la cobertura a sus socios de los riesgos asegurados mediante una prima fija pagadera al comienzo del período del riesgo (art. 13); de las mutuas a prima variable, es decir, las que fundadas sobre el principio de ayuda recíproca, tienen por objeto la cobertura por cuenta común de los riesgos asegurados a sus socios o mutualistas, mediante el cobro de derramas con posterioridad a los siniestros (art. 14). A las mutuas a prima fija les impone la obligación de inscripción en el Registro Mercantil para su constitución mientras que para las mutuas a prima variable limitaba el ámbito de actuación a un único ramo y en un ámbito territorial reducido (menos de 2 millones de habitantes o una provincia) ${ }^{23}$.

22 Por ejemplo, para ser considerada asociación mutua de seguro señala la exigencia de «ser entidad aseguradora la personalidad colectiva y mancomunada de todos los asociados» (art. 33.1) y "ser únicamente asegurados o contratantes con dicha personalidad colectiva aseguradora las personas que, mediante la aceptación simultánea de una póliza y de los estatutos y reglamentos, tomen, a su vez, carácter de aseguradores» (art. 33.2).

23 Para detalles sobre su régimen, Duque Domínguez, "Mutuas y cooperativas en la nueva legislación ordenadora del seguro privado», Comentarios a la Ley de Ordenación del Seguro Privado, Dir. Verdera, Madrid, 1988, pp. 367 y ss.; y la citada obra de TIRADO SUÁREZ, passim. 
El Real Decreto 1248/1985 que aprobó el Reglamento de Ordenación del Seguro Privado regulaba, con cierto detalle, los derechos y obligaciones de los socios de las mutas, los órganos de gobierno (Junta General y Consejo de Administración) y el contenido mínimo de los estatutos (arts. 24-39). Se puede reconocer en esta normativa de los años ochenta un gran avance técnico en la regulación legal de las mutuas de seguros respecto a la anterior, teniendo como referencia el régimen legal de la sociedad anónima

Cabe mencionar que la Ley del seguro de 1984 fue objeto de un recurso de inconstitucionalidad por los gobiernos vasco y catalán, precisamente por la regulación que contenía sobre las cooperativas de seguros, las mutuas y las mutualidades de previsión social que dichas Autonomías consideraban de su competencia exclusiva y que se resolvió por la conocida STS 86/1989, que declaraba respecto a las mutua de seguros que las competencias autonómicas quedaban reducidas al desarrollo y ejecución de las bases estatales ya que el Estado tenía competencia exclusiva en la legislación básica de la actividad aseguradora por ser legislación mercantil (art. 149.1.6. ${ }^{a}$ CE). No obstante, aunque la mayoría de Comunidades Autónomas han asumido competencias sobre mutuas de seguros, a diferencia de lo que ha ocurrido con las mutualidades de previsión social no integradas en la Seguridad Social24, ninguna de ellas ha promulgado hasta ahora una normativa de desarrollo de la legislación básica del Estado, aunque en las leyes ordenadoras de seguros privados aparece muy claro la delimitación de qué preceptos tienen carácter básico y cuáles no ${ }^{25}$. Supongo que dado el escaso número de mutuas de seguros que tradicionalmente operan en nuestro mercado asegurador (en la actualidad unas treinta), y algunas de ellas, las más importantes, de actuación supra autonómica, no les merece la pena a las Comunidades Autónomas desarrollar dicha normativa.

Por su parte, la Ley 30/1995 de Ordenación de los Seguros Privados reguló en su artículo 9 el régimen básico de las mutuas a prima fija y en el artículo 10 el de las mutuas a prima variable, desarrollados respectivamente en los artículos 11 a 22 del Reglamento de Ordenación y Supervisión de los Seguros Privados, aprobado por el Real Decreto 2486/1998 (se cita ROSSP). En dichos preceptos no se observan grandes diferencias del régimen legal de las mutuas respecto a la normativa anterior (aunque es llamativo el cambio de de-

24 En Cataluña la Ley 10/2003, en el País Vasco la Ley 5/2012, etc.

25 Disp. final 1. ${ }^{a}$ LOSSP, disp. final 9. ${ }^{a}$ LOSSEAR, etc. 
nominación de los órganos sociales: Asamblea General y Consejo de Administración) $)^{26}$.

Por último, la LOSSEAR dedica a las mutuas de seguros un sólo artículo, el cuarenta y uno (titulado precisamente mutuas de seguros) sin apenas hacer referencia en otros preceptos de la Ley a esta forma alternativa de explotación de seguros. Dicho precepto, muy parco, se limita a dar un concepto legal de mutua de seguros (apdo. 1), a reconocer la posibilidad de constituir grupos mutuales (apdo. 2) y a establecer algunas normas relativas a la liquidación de la mutua y determinados supuestos de modificaciones estructurales (apdo. 3).

A principios de diciembre de 2015 se promulgó el Real Decreto 1060/2015 que aprueba el Reglamento de la Ley (ROSSEAR). La norma reglamentaria, aparte de algunos artículos dispersos por el texto, dedica a las mutuas de seguros tres grupos de normas. Uno, las normas relativas al acceso a la actividad aseguradora y reaseguradora de las mutuas en el Capítulo I del Título II [arts. 4.1, letra a) y b), 7.1, letra b), 14 y 20]; otro, las disposiciones relativas a las mutuas del régimen de modificaciones estructurales de entidades aseguradoras en la Sección segunda del Capítulo V del Título III (arts. 106-1014); y, por último, el artículo 211 que es el único precepto que conforma el Capítulo IV del Título $\vee$ sobre supervisión de los grupos de entidades aseguradoras y reaseguradoras y que lleva por título Grupos mutuales.

Si se compara la regulación sobre mutuas contenida en la LOSSEAR y en su Reglamento de desarrollo con el contenido que tenía la LOSSP y su reglamento, se comprueba como la norma anterior era mucho más extensa en lo que se refiere a la regulación del régimen legal de las mutuas. La justificación está en una anunciada regulación reglamentaria para este tipo de entidades. En particular, como manifiesta la Exposición de Motivos de la Ley (IV), para las mutuas de seguros se mantiene en vigor el régimen contenido en la LOSSP «hasta que se acometa una regulación específica de las mutuas y, en particular, de su régimen jurídico de disolución, transformación, fusión, escisión y cesión global de activo y pasivo», vigencia que se detalla en la disposición derogatoria de la norma (letra g), que dejaba vigentes los artículos 9, 10 y 24 de la LOSSP por lo que se refiere a las mutuas de seguros (aunque el artículo 10 es inaplicable por referirse a las mutuas a prima variable que ahora no se permiten y el 24 a los procesos de modificaciones estructurales y agrupamiento de las mutuas, que también entra en colisión

26 Para los aspectos esenciales del régimen de las mutuas de seguros de la LOSSP y del ROSSP, remitimos para su estudio a MORENO, Mutualidades, Cooperativas, Seguro y Previsión Social, Madrid, CES, Madrid, 2000, pp. 65 y ss. 
con la normativa actual). Por su parte, y en la misma línea, el ROSSEAR deroga el ROSSP, salvo lo dispuesto en el artículo 11, en lo que no se oponga al artículo 41.3 LOSSEAR (apdo. I) y en los artículos 12, 13, 14, $15,16,17,18,19,20,21$ y 22 (apdo. II), que constituyen el grueso del régimen de las mutuas de seguros de la anterior normativa (aunque de nuevo sorprende que se deje expresamente vigente el artículo 22 relativo a las mutuas a prima variable, que hay que considerar derogado por ser su régimen contrario a la LOSSEAR).

Esta pervivencia de normas de la anterior normativa, con un régimen escueto pero en algunos puntos novedosos de la LOSSEAR y del ROSSEAR genera, por un lado, ciertas dificultades interpretativas de integración de normas ${ }^{27}$ y, por otro, la sensación de que el régimen legal de las mutuas de seguros apenas ha sufrido cambios de calado más allá de la prohibición de las mutuas a prima variable, determinados aspectos de operaciones de modificaciones estructurales en las que participen mutuas y la posibilidad de constituir grupos mutuales. Se supone que para el anunciado desarrollo reglamentario en esta materia, se contará, de un lado, con gran parte del contenido que se ha dejado expresamente vigente para estas entidades en la LOSSP y ROSSP (normas aplicables, estatutos, derechos y obligaciones de los mutualistas, órganos de gobierno, etc.) que se completará con la regulación que sobre las mutuas contiene la LOSSEAR y el ROSSEAR (modificaciones estructurales y grupos mutuales esencialmente) y con algunas de las previsiones legales que contenía el Proyecto de Ley de Supervisión de los Seguros Privados de julio de 2011 (se cita PLSSP) que dedicaba a las mutuas de seguro (art. 31) ${ }^{28}$.

Si entrar en grandes detalles sobre la regulación proyectada en 2011, si cabe comentar que ésta pretendía la simplificación el régimen legal de las mutuas, garantizar la solidez financiera de estas entidades y materializar su carácter diferencial como entidad sin ánimo de lucro mediante la exigencia de políticas específicas de retorno a sus mutualistas y de gobierno corporativo. Respecto a esto último, las mutuas

27 Como ha puesto de manifiesto Tous GRANDA, «La falta de la regulación de la mutua de seguros en la Ley 20/2015, de 14 de julio, de Ordenación, Supervisión y Solvencia de las entidades aseguradoras y reaseguradoras», en Libro de Actas III Congreso Nacional de Ordenación, Solvencia y Supervisión en Seguros Privado, Dir. Bataller y Peñas, Valencia, 2016, pp. 431-442.

28 Que analicé en VARgas VASSEROt, «Las Mutuas de Seguros. Especial referencia a la doble condición de socio y asegurado del mutualista», en Supervisión en Seguros Privados. Hacia solvencia II. Actas del Congreso de Ordenación y Supervisión en Seguros Privados. Valencia, 15 y 16 de septiembre de 2011, Cuñat Edo y Bataller Grau (Dirs.), Valencia, 2013, pp. 577-587. 
debían elaborar anualmente un informe de gobierno corporativo que contendrá información sobre la composición, funcionamiento y retribución del consejo de administración y de sus comisiones; las operaciones vinculadas y los conflictos de interés de la mutua de seguros con sus administradores y con quienes realicen la dirección; la organización y el funcionamiento de la asamblea general; los principios básicos de las políticas de gestión de riesgos, el control y la auditoría interna, y, en su caso, la externalización de sus funciones o actividades; y el grado de seguimiento de las recomendaciones de gobierno corporativo del sector asegurador, o, en su caso, la explicación sobre la falta de seguimiento de dichas recomendaciones.

\section{Naturaleza jurídica de las relaciones mutualistas en las mutuas de seguros}

Una cuestión nuclear, escasamente tratada por nuestra doctrina, es el análisis de la relación jurídica que une al mutualista y a la mutua, a través de la cual se desarrolla el objeto social de la entidad ${ }^{29}$. La importancia de determinar la naturaleza jurídica de esta relación mutualista, en el sentido de si es una relación contractual, una relación societaria o una relación híbrida, deriva de que de ello dependerá el régimen jurídico aplicable para resolver determinadas situaciones de conflicto. Si se considera que la relación mutualista en las mutuas de seguros es una relación contractual distinta a la societaria, habrá que admitir la existencia de una duplicidad de relaciones jurídicas conformadas, de un lado, por el contrato de sociedad; y de otro, por las relaciones de carácter contractual independiente del contrato social.

Las tesis societarias o corporativas consideran en cambio que en el marco de relaciones típicas de las mutualidades con sus socios no hay una pluralidad de contratos sino un propio contrato de sociedad en el que existen unas cláusulas inherentes típicas de este tipo de socieda-

29 De los pocos autores que en España la ha tratado: TIRADO SUÁrEZ, «La relación mutualista entre socio y cooperativa en el Derecho de seguros vigente», en Derecho de Sociedades. Libro homenaje a Fernando Sánchez Calero, t. V, Madrid, 2002, pp. 44814505; VARGAS VASSEROT, La actividad cooperativizada y las relaciones de la cooperativa con sus socios y con terceros, Cizur Menor, 2006, pp. 138-143; MARTínez SeGoviA, "La relación cooperativizada entre la sociedad cooperativa y su socios: naturaleza y régimen jurídico», $R d S, \mathrm{n}^{\circ} 25$, pp. 221 y s. Aunque breve, de interés es la reflexión que sobre la cuestión hace GARRIGUES, op. cit., p. 28, nota 30. En Derecho comparado, recoge las distintas tesis sobre la naturaleza de la relación mutual en las mutuas de seguros DONATI, Trattato del Diritto delle Assicurazioni Private, vol I, cit., pp. 213-219. 
des. Los defensores de esta tesis niegan que en la participación del socio en la sociedad exista una dualidad de relaciones jurídicas, porque la consecución de los bienes o servicios que la entidad procura al socio, es el elemento integrador de la relación social, sustanciándose con ello la mutualidad, y que precisamente es de este modo como se obtiene el fin mutualista de la mutua de seguros.

Lo cierto es que el legislador español a la hora de calificar la naturaleza jurídica de las relaciones socio-sociedad en los tipos sociales de carácter mutualista no ha tenido un tratamiento uniforme y algunas veces se ha decantado por la naturaleza contractual de esa relación, otras, las menos, opta por el carácter societario (art. 80.1 LCOOP para las Cooperativas de Trabajo Asociado) y otras, las más, ha guardado silencio al respecto ${ }^{30}$. Veamos en concreto cómo ha regulado la cuestión en el marco de las mutuas de seguros.

Hay que partir que en nuestro Derecho positivo, desde siempre, la condición de mutualista es inseparable de la del tomador del seguro o del asegurado [art. 33.2 Reglamento de 1908, art. 12.5 Ley de 1954, art. 9.2, Letra b) LOSSP y art. 41.1 LOSSEAR] y aquélla se adquiere a través del contrato de seguro [art. 11, letra a) ROSSP]. No obstante, si estas posiciones subjetivas del seguro están ocupadas por personas diferentes, en principio el tomador será a su vez mutualista, salvo que en la póliza de seguros expresamente se haga constar que deba serlo el asegurado [art. 11.1, letra a) ROSSP).

Precisamente el principal rasgo diferenciador de las mutuas respecto a las entidades de seguros de tipo capitalista es que es simultánea la conclusión del contrato de seguro y la adquisición de la cualidad de socio. Si en un momento histórico se llegó a defender la primacía del el contrato social sobre el del seguro, desde que las mutuas operan como una entidad más, ofertando seguros en masa, adquiere considerablemente más peso la relación aseguradora que la de la sociedad, como se reconoce por la propia Ley al establecer que la consideración de mutualista se adquiere por la suscripción del contrato de seguro ${ }^{31}$. Ya no cabe decir que la diferencia entre las mutuas de seguros de las sociedades anónimas de seguros era que en las primeras, para la prestación del seguro, no hacía falta la suscripción de

30 Vargas Vasserot, op. cit., pp. 131-144; Martínez Segovia, op. cit., pp. 206-220.

31 TIRADO SUÁreZ, op. cit., pp. 4481 y s., reconoce la existencia esa separación entre las relaciones mutuales y contractuales, pero apunta que la preferencia del contenido del contrato de seguro se ha impuesto con el desarrollo de las mutuas como empresas aseguradoras. 
un contrato ulterior al social ${ }^{32}$, puesto que es precisamente por la contratación del seguro como el cliente de la empresa aseguradora se convierte en mutualista y no al revés.

En las mutuas de seguros, a diferencia de otras entidades asociativas, no se exige para el ingreso como miembro una aportación al capital social o fondo mutual ni, con carácter general, una cuota de entrada por lo que en rigor la suscripción del contrato de seguro es el único requisito para el ingreso en la mutua, y por ello los estatutos de la entidad deben entregarse al mutualista en el momento de la firma del contrato de seguro [art. 11.1, letra a) in fine ROSSP]. Dada la trascendencia jurídica de la suscripción del seguro, debería cuidarse sobremanera la información relativa al significado que tiene su entrada como miembro de la entidad. Es un hecho conocido el poco cuidado que tienes muchas entidades aseguradoras a la hora de informar y facilitar las condiciones generales de los seguros a sus clientes que a veces se les da días después de su contratación (no es inusual el envío por correo - ni siquiera certificado-). En el caso de las mutuas de seguros la importancia de un buen asesoramiento y de facilitar adecuadamente toda la documentación del seguro, se acentúa, puesto que debe también hacerse entrega de los estatutos sociales.

Reconocida la doble relación contractual, societaria y aseguradora, que al menos en su génesis están íntimamente unidas ya que para el socio nacen en un mismo acto (la suscripción del seguro), habrá que precisar hasta qué punto son relaciones independientes y en qué medida el régimen jurídico de una relación influye en el de la otra. Esta cuestión y su respuesta están íntimamente relacionadas con la de la naturaleza jurídica del vínculo socio-sociedad en las sociedades de carácter mutualista.

Interdependencia entre ambos tipos de relaciones es evidente que las hay, como lo demuestra la posibilidad de que el contrato de seguro contenga aspectos del contenido del contrato social — por ejemplo, si los estatutos establecen la responsabilidad de los mutualistas por las deudas sociales, esta circunstancia «deberá destacarse en las pólizas de seguros» [art. 9.2, letra d) LOSSP]. Y viceversa, en cuanto que en teoría los estatutos sociales pueden imponer obligaciones a los mutualistas relacionadas con el contrato de seguro, ya que la ley no limita en ese sentido el contenido de los derechos y obligaciones de los socios [art. 12, letra b) y art. 14, letra a ) ROSSP], pero en todo caso habrá que respetar el necesario trato igualitario a los mutualistas (art. 13 ROSSP) y cumplir los requisitos de incorporación de su contenido dentro de las condiciones generales del contrato de seguro (art. 3 LCS).

32 Donati, op. cit., pp. 216-218. 
Pero también es evidente la autonomía de ambas relaciones. Por ejemplo, es de obligada previsión estatutaria el "sometimiento de los mutualista, en cuanto tales y no como tomadores o asegurados, a la jurisdicción de los Tribunales del domicilio social de la entidad» [art. 12, letra j) ROSSP], mientras que para los conflictos que surjan en el marco del contrato de seguro serán competentes los jueces del domicilio del asegurado, siendo además nulo cualquier pacto en contrario (art. 24 LCS).

En definitiva, para concretar el régimen jurídico aplicable a las relaciones mutualistas habrá que analizar cuál ha sido la voluntad de las partes (mutualista/mutua), y en caso de que se pretenda afectar el contrato de seguro con el contenido del contrato social, habrá que cumplir con las previsiones de la LCS. Recordemos que los contratos de seguros son contratos sometidos a condiciones generales, y que normalmente el asegurado es un consumidor, por lo que será de aplicación las normas tuitivas de los consumidores en general y de los asegurados en particular. Por ello, si se quiere que el contenido del contrato social se considere incorporado al contrato de seguro habrá que cumplir con las exigencias del artículo 3 de la LCS, en cuanto a que sean cláusulas redactadas de forma clara y precisa, contenidas en la póliza o documento complementario (como ocurre cuando se entregue una copia de los estatutos) y suscritas por el asegurado. Y en caso de que las cláusulas estatutarias limiten los derechos contractuales de los asegurados, para obligar al tomador del seguro o asegurado, deberán destacarse de modo especial y ser específicamente aceptadas por escrito.

\section{Principales novedades del régimen legal de las mutuas y el riesgo de desmutualización del sector}

\section{a) Continuidad con el régimen anterior}

De la integración del artículo 41 LOSSEAR, del artículo 211 ROSSEAR, del 9 TRLOSSP y de los artículos 11-24 ROSSP, todos ellos como hemos explicado vigentes, se deduce que las mutuas de seguros en nuestro ordenamiento tienen las siguientes características legales:

- Son sociedades mercantiles sin ánimo de lucro

- Tienen como objeto la cobertura a sus socios de los riesgos asegurados.

- Tiene que operar necesariamente a prima fija pagadera al comienzo del periodo de riesgo. 
- La condición de mutualista es inseparable de la de tomador o asegurado.

- Tienen que tener como mínimo 50 miembros.

- Los mutualistas pueden cobrar un interés limitado al legal del dinero por sus aportaciones al fondo mutual.

- Con carácter general, los mutualistas no responden de las deudas sociales, salvo mención estatutaria en contra y con el límite del valor de la prima.

- Los resultados del ejercicio darán lugar a derramas activas a favor del mutualista o derramas pasivas en su contra.

- Los mutualistas tienen un derecho de reembolso de lo aportado al fondo mutual en caso de baja.

- En caso de disolución, los socios tienen derecho, como mínimo, a la liquidación de la mitad del patrimonio social.

- Los derechos (políticos, económicos y de información) y las obligaciones de todos los mutualistas son los mismos.

- Cada socio tiene un voto y tiene derecho a asistir a la asamblea y ser elegido para cargos sociales.

- Los órganos de gobierno (Asamblea General y Consejo de Administración) han de tener funcionamiento, gestión y control democrático.

- Las mutuas se pueden integrar en grupos mutuales cuando cumplan una serie de requisitos.

- Los procedimientos de modificaciones estructurales están limitados y reglamentados de manera especial.

- El régimen supletorio, a falta de disposición legal, reglamentaria o estatuaria especial, es la ley aplicable a las sociedades anónimas.

De lo dicho, se desprende que son tres las principales novedades que aporta la LOSSEAR y su reglamento de desarrollo al régimen legal de las mutuas vigente con la LOSSP: la prohibición de mutuas a prima variable; un régimen novedoso de modificaciones estructurales cuando participe una mutua; y el reconocimiento de la posibilidad de constituir grupos mutuales basados en vínculos no de capital.

b) La proscripción legal de las mutuas a prima variable

Uno de los cambios más llamativo de la LOSSEAR respecto a la normativa anterior es la prohibición de las mutuas a prima variable, que son aquellas en las que la cobertura de sus asegurados se realiza me- 
diante el cobro de derramas con posterioridad a los siniestros, y no como las mutuas a prima fija en las que los tomadores del seguro pagan una cantidad de manera anticipada al comienzo de cada período de riesgo. Las limitaciones respecto a la actividad aseguradora a realizar por las mutuas a prima variable, la exigencia de aportación de una cuota de entrada y constitución de un fondo de maniobra, la incertidumbre de las cuantías de las derramas a pagar hasta que concluye el período en curso y la responsabilidad mancomunada de los miembros proporcional al importe de los respectivos capitales asegurados, entre otras circunstancias, hacían que la constitución de este tipo de mutuas fuera muy inusual y sólo para la cobertura de riesgos ciertamente limitados. En 2010 sólo existían tres mutuas de seguros a prima variable en nuestro mercado asegurador y todas ellas operaban en el ramo de incendios y elementos de la naturaleza. La Sociedad de Previsión de Seguros Mutuos de Incendios de Ferrol, se liquidó ese mismo año por el Consorcio de Compensación de Seguros. Las otras dos, Seguros Mutuos a Prima Variable de Incendios de Casas del Valle de Mena y la Unión Montijana Seguros contra Incendios estaban localizadas en la provincia de Burgos y la primera se liquidó en 2012 y la segunda en 2016, desapareciendo así la última mutua a prima variable de nuestro país con más de medio siglo de existencia (se constituyó en 1957).

En cualquier caso, como establece la disposición transitoria primera LOSSEAR, titulada "Régimen de las mutuas de seguros, mutualidades de previsión social y cooperativas a prima variable», las entidades de esta clase que a la entrada en vigor de esta Ley estuvieran autorizadas para el ejercicio de la actividad aseguradora no podrán seguir ejerciéndola con esa forma jurídica debiendo, en el plazo de un año desde la entrada en vigor de la LOSSEAR, transformarse en mutuas de seguros a prima fija, en sociedades anónimas o bien acordar su disolución y liquidación.

Aunque es cierto que el uso de este tipo de mutuas es muy residual, la tendencia manifiesta a homogeneizar la forma de actuar de los distintos tipos de entidades de seguros y de canalizar la industria a través de grandes entidades de seguros, olvida el origen y carácter mutualista del seguro y limita grandemente las posibilidades de un aseguramiento a pequeña escala y que históricamente ha funcionado como prototipo de explotación de seguros basados en la ayuda mutua. Y no sirve como justificación el hecho de que se quita esta modalidad de seguros mutuos porque no se utiliza, puesto que menos se usan las cooperativas de seguros (no hay ni ha habido nunca ninguna autorizada) y siguen estando reguladas en el texto de la Ley. Como se ha señalado, la diversidad empresarial es un valor que hay que cuidar y aún 
más en un sector como es el asegurador donde la actividad económica está cada día más estandarizada, debe defenderse la existencia de una pluralidad de modelos de empresa, como el que representan las mutuas de seguros ${ }^{33}$.

\section{c) El régimen de modificaciones estructurales}

La sección segunda del Capítulo V (Operaciones societarias) del Título III (Ejercicio de la actividad) del ROSSEAR se dedica a las Modificaciones estructurales (arts. 106-114) a las que se pueden ver sometidas las entidades aseguradoras, régimen que debe ser completado por la regulación contenida por la Ley 3/2009 sobre modificaciones estructurales de las sociedades mercantiles (LMESM). Dicha sección se divide en varias subsecciones, cada una de ellas dedicada a una particular operación de modificación estructural y casi todas contienen alguna referencia explícita a las mutuas de seguros.

Respecto a la transformación de entidades aseguradoras, el ROSSEAR parte de una relación excesivamente cerrada de operaciones de transformación que se pueden realizar, sancionando con la nulidad cualquier transformación de una entidad aseguradora en una sociedad del tipo distinto a los previstos en la norma (art. 106.2). En particular, para las mutuas de seguros el régimen es muy restrictivo y únicamente se permite su transformación en sociedades anónimas de seguros [art. 106.1, letra b)] y sólo se admite que las mutualidades de previsión social se transformen en mutuas de seguros [art. 106.1, letra d)], con lo que ni las cooperativas de seguros ni las sociedades anónimas de seguros se pueden transformar en este tipo de entidad.

Para el caso de transformación de una mutua en una sociedad anónima de seguros, se concede un derecho de separación de los mutualistas que no hubieran votado a favor del acuerdo de transformación, en los términos previstos en el artículo 15 LMESM (art. 106.4). En la valoración de las participaciones sociales que corresponden al socio que se separa se debe tener en cuenta las aportaciones que realizó al fondo mutual y el reembolso de la parte de la prima no consumida de los contratos de seguro que se resuelvan. Por lo demás, no hay mayores peculiaridades en el régimen de transformación de mutuas en sociedades anónimas distintas a algunas especialidades en cuanto a la docu-

33 FajaRdo García, «Entidades mutualistas en el mercado asegurador», en Supervisión en seguros privados: Hacía solvencia II, Dir. Cuñat y Bataller, Valencia, 2013, pp. 531-534. 
mentación que se tiene que presentar a la DGSFP para obtener la preceptiva autorización del Ministro de Economía y Competitividad para acometer dicha transformación (art. 107).

En cuanto al régimen de la fusión de entidades aseguradoras, que se detalla en la subsección 2. ${ }^{a}$, De nuevo se perciben importantes limitaciones para las mutuas de seguros respecto a las sociedades anónimas de seguros. Así, por ejemplo, mientras que se establece que cualesquiera entidades aseguradoras podrán fusionarse en una sociedad anónima de seguros y que éstas podrán absorber entidades aseguradoras, cualquiera que sea la forma que éstas revistan (art. 109.1), las mutuas de seguros sólo podrán fusionarse con entidades de su misma naturaleza y forma, y únicamente podrán absorber a otras entidades aseguradoras con forma distinta a la de sociedad anónima de seguros, esto es, mutualidades de previsión social y cooperativas de seguros (art. 109.2). No obstante, esta última limitación, las mutuas podrán absorber entidades de cualquier naturaleza íntegramente participadas por ellas, con la genérica salvedad de que las entidades aseguradoras no pueden fusionarse con entidades no aseguradoras, ni absorberlas ni ser absorbidas por entidades no aseguradoras (art. 109.4).

Respecto a la cesión global del activo y pasivo, el ROSSEAR señala que resultarán de aplicación los preceptos relativos a la fusión, pero, a diferencia de lo establecido en el artículo 109.2, las mutuas de seguros podrán ser beneficiarias de la cesión global de activo y pasivo realizada por cualquier entidad (art. 112, 2. ${ }^{\circ}$ ). Por último, acerca de la escisión de entidades aseguradoras, la subsección 4 que las regula, parte de la aplicación de las mimas limitaciones que existen para la fusión, sin existir ninguna norma específica para estas operaciones cuando concurren mutuas de seguros.

De todos estos procesos de modificación estructural, sin duda, el que más interés ha despertado ha sido el de transformación. En los últimos años hemos vivido en España un proceso de desmutualización de algunas de las principales mutuas de nuestro país. Entre ellas destaca, la de la Mutualidad de la Agrupación de Propietarios de Fincas Rústicas de España, más conocida por su acrónimo MAPFRE, por haber sido la empresa líder del sector asegurador español durante décadas y las mutuas de seguros más importante de España con gran implantación internacional. Su proceso de transformación en sociedad anónima iniciado en 2006 tuvo una gran repercusión mediática, sobre todo por las dificultades que se encontró la entidad para contactar con millones de mutualistas que podían elegir entre dinero (74,52 euros) o acciones (23) de la nueva sociedad anónima que se creaba para compensar la pérdida de condición de mutualista. En marzo de 2007 comenzaron 
a cotizar las acciones de MAPFRE S.A. y en 2010 todavía quedaban 2,8 millones de personas, la mitad de los mutualistas sin reclamar ni el dinero (unos 210 millones de euros) ni las acciones. Sin entrar en los motivos argüidos por la propia entidad para proceder a esta desmutualización (básicamente globalización de la empresa y cotización en bolsa), no deja de sorprender que en una asamblea con una presencia muy escasa de la masa social de la mutua, se pueda decidir su transformación sociedad anónima y una ampliación de capital social que dejaba claro las posiciones de control de los accionistas mayoritarios.

En 2011, siguió parecidos pasos la Mutua General de SegurosEuromutua (MGS) otra importante mutua del sector (entre las 10 primera mutuas y entre las 50 del ranking general de entidades de seguros entre los últimos años), que aprobó su transformación en sociedad anónima de seguros y que ha pasado a denominarse MGS Seguros $y$ Reaseguros S.A.

Pero también ha habido movimientos de fusiones en el sector de mutuas. Así, por ejemplo, en 2012 se fusionó FIATC, Mutua de Seguros y Reaseguros y la entidad Previred, Mutualidad de Previsión Social. En 2014 Pelayo, Mutua de Seguros y Reaseguros absorbió a Mutral, Mutua Rural de Seguros. Por su parte, aunque no fue una fusión propiamente dicha, Mutua Madrileña, cuyo grupo en 2015 fue líder del sector asegurador español en volumen de primas, adquirió en 2011 a la Caixa el $50 \%$ de Vidacaixa-Adeslas.

\section{d) Grupos mutuales}

La principal novedad que presenta el nuevo régimen legal del seguro privado respecto a su precedentes es la regulación de los grupos mutuales que simplemente anuncia el artículo 41.2 LOSSEAR ( Las mutuas podrán constituir grupos mutuales conforme a los requisitos que se establezcan reglamentariamente») y que desarrolla con cierto detalle el denso artículo 211 ROSSEAR, que con el título Grupos mutuales, conforma el único artículo del Capítulo IV, que repite denominación, del Título $V$ dedicado a la supervisión de grupos de entidades aseguradoras y reaseguradoras.

El contenido de dicho artículo está inspirado en los principios enunciados en esta materia por la Directiva Solvencia II. En particular, su considerando 98 disponía que «con arreglo a la legislación comunitaria y nacional, las empresas, en particular las mutuas y sociedades mutuas, deben poder constituir concentraciones o grupos, no mediante vínculos de capital, sino mediante relaciones oficiales, fuertes y estables, basa- 
das en un reconocimiento contractual o de otro tipo que garantice una solidaridad financiera entre dichas empresas» y que "cuando se ejerza una influencia dominante mediante una coordinación centralizada, las empresas deben ser supervisadas de conformidad con las mismas normas que se aplican a los grupos constituidos sobre la base de vínculos de capital a fin de alcanzar un nivel de protección adecuado de los tomadores de seguros y la igualdad de oportunidades entre los grupos». Por su parte, el artículo 212.1, c) ii) de la Directiva, define al grupo mutual a todo conjunto de empresas que se base en el establecimiento, contractual o de otro tipo, de vínculos financieros sólidos y sostenibles entre esa las empresas, y que puede incluir mutuas o asociaciones de tipo mutualista, siempre que una empresa (matriz), ejerza mediante coordinación centralizada, una influencia dominante en las decisiones de todas las empresas que forman parte del grupo (filiales).

La integración de las mutuas de seguros nunca ha estado vedada a este tipo de entidades, incluso se defiende que en estas entidades rige también el principio de intercooperación típico de las cooperativas por la identidad de caracteres que tienen ambos tipos de sociedades de la economía social ${ }^{34}$. De un lado, hay una integración institucional para defender intereses comunes y difundir este peculiar modelo de negocio del seguro como ocurre a nivel mundial con la Federación Internacional de Cooperativas y Mutuas de Seguros (ICMIF), entidad surgida en 1922 como el Comité de Seguros de la Alianza Cooperativa Internacional (ACl) que desde 1992 tiene autonomía propia, que agrupa a la mayoría de federaciones de mutuas de seguros del mundo. En España no hay una confederación de mutuas de seguro, a diferencia de lo que ocurre con las mutualidades y las mismas, sin apenas distinción grupal, se integran en UNESPA (Asociación Empresarial del Seguro).

De otro lado, existen ejemplos de integraciones empresariales de mutuas de seguros, aunque lo normal ha sido acudir antes a la vía de fusiones de mutuas que a la creación de grupos de mutuas, lo que no quita que todas las grandes mutuas conformen a su vez grupos empresariales, liderados por la propia mutua. Pero estos son grupos jerárquicos, dirigidos por la mutua y compuestos por sus sociedades filiales, que en la mayoría de las veces son sociedades anónimas y sociedades de responsabilidad limitada. En estos casos es de aplicación lo previsto

34 Así lo defiende Moreno Ruiz ( «Las empresas de participación aseguradoras y la concentración», REVESCO, núm. 73, 2001, pp. 81-94), aunque no exista en la normativa de mutuas una referencia expresa, como suele haberlas en las leyes cooperativas española, a la vigencia de los principios cooperativos en general y, en especial al sexto principio de la $\mathrm{ACl}$ de cooperación entre cooperativas. 
en el artículo 42 C.com, en la redacción que dio la Ley 63/2003, y por la que la sociedad dominante de un grupo de sociedades (que ya no tiene que tener naturaleza mercantil, como se exigía antes, por lo que pueden ser una mutua) está obligada a formular las cuentas anuales y el informe de gestión consolidados. Según este precepto existe un grupo cuando «varias sociedades constituyan una unidad de decisión», que se presume que existe cuando una sociedad (dominante) sea socia de otra sociedad (dominada) y se den una serie de circunstancias (posea o pueda disponer de la mayoría de los derechos de voto; tenga la facultad de nombrar o destituir a la mayoría de los miembros del órgano de administración; y/o haya designado exclusivamente con sus votos a la mayoría de los miembros del órgano de administración en el momento en que deban formularse las cuentas anuales y durante los dos años anteriores) o cuando, por cualesquiera otros medios, una o varias sociedades se hallen bajo dirección única (por ejemplo, cuando la mayoría de los miembros del órgano de administración de la sociedad dominada sean miembros del órgano de administración o altos directivos de la sociedad dominante o de otra dominada por ésta).

Pero los grupos a los que le presta atención el legislador de seguros no son estos típicos grupos jerárquicos, sino a los grupos paritarios, en lo que no existe una relación de dependencia entre las sociedades agrupadas, de manera que la dirección unitaria no se impone por una entidad superior sino que la gestión del grupo se caracteriza por una coordinación horizontal a través de acuerdos de colaboración mutua entre las mutuas miembros ${ }^{35}$. De este modo, en los grupos paritarios la dirección unitaria es el elemento que aporta cohesión al grupo y en su determinación intervienen, en igualdad, todas las sociedades del grupo. La unidad de decisión, por tanto, recorre un camino inverso que en los jerárquicos o de subordinación, por lo que se pueden representar el grupo como una pirámide invertida en la que la cabeza de grupo se sitúa en una posición inferior y en la base, pero por arriba las sociedades que lo componen.

Pues bien, una de las novedades de la LOSSEAR es el reconocimiento de la posibilidad de crear grupos de entidades sin vinculación de capital, como es el caso específico de las mutuas, posibilidad desarrollada por el artículo 211 ROSSEAR ${ }^{36}$. De esta norma se desprende

35 A estos grupos le ha dedicado especial atención la doctrina al tratarlos en el ámbito de las sociedades cooperativas: EMBID IRUJO, «Problemas actuales de la integración cooperativa», RDM, núm. 227, p. 14.

36 Sobre los detalles del régimen I de los grupos mutuales, aquí apenas apuntado: GIRGADO PERANDONES, «Una aproximación a la regulación de los grupos de entidades de seguros en la LOSSEAR», en Libro de Actas III Congreso Nacional de Ordenación, Solvencia 
que lo definitorio del grupo mutual es que lo que une al grupo de mutuas no son vínculos de capital sino vínculos contractuales. Según este precepto, las mutuas de seguros podrán constituir grupos mutuales, mediante la creación de una sociedad de grupo mutual, que será una sociedad anónima participada por todas ellas. Esta entidad matriz le corresponderá la dirección de las políticas financieras y de explotación de todas las entidades el grupo y su objeto social exclusivo será el establecimiento y la administración de vínculos de solidaridad financiera sólidos y sostenibles entre entidades que formen parte del grupo, así como el diseño y ejecución de políticas estratégicas y comerciales del grupo y la prestación de servicios comunes. Si la entidad matriz está domiciliada en España, le corresponde a la DGSFP la autorización de la constitución, modificación y disolución del grupo mutual

En cuanto a su régimen jurídico, tal como establece el ROSSEAR, el grupo mutual se regirá por lo dispuesto en sus estatutos y en los convenios de adhesión suscritos con cada una de las entidades integrantes del grupo (art. 211.5), lo que lo confirma la existencia de un contrato de grupo o contrato de integración ${ }^{37}$. Los convenios de adhesión al grupo mutual, que deben ser aprobados por la asamblea general de cada una de las entidades participes del grupo y por la DGSFP, se tienen que elevar a escritura pública y depositar en el Registro Mercantil. Los convenios incluirán los derechos y obligaciones, tanto políticas como financieras, de cada una de las entidades del grupo, hacia el resto de las entidades del grupo y hacia la propia sociedad matriz, así como aspectos relativos a las estrategias comerciales y operativas del grupo. La duración de estos convenios se establece, para darle estabilidad al mecanismo de integración, como mínimo de diez años y deberán incluir un régimen de penalizaciones por baja que refuerce la permanencia de las entidades en el grupo.

La posibilidad de crear grupos sobre la base de vínculos contractuales constituye un mecanismo especialmente interesante para las mutuas de seguros tras los requisitos de solvencia vigentes, ya que estas entidades, por sus propias características, tienen dificultades de acceso a determinadas fuentes de financiación y no pueden entablar vínculos de capital con otras mutuas ${ }^{38}$.

y Supervisión en Seguros Privado, Dir. Bataller y Peñas, Valencia, 2016, pp. 539-5454.; y SAN PEDRO MARTÍNEZ, y VIDAL, "Apuntes sobre los grupos mutuales en el Proyecto de Ley de Supervisión de los Seguros Privados», en la misma obra, pp. 605-617.

37 GIRGADO PERANDONES, op. cit., p. 543.

38 Como señalan SAN PEDRO MARTíNEZ, y VIDAL, op. cit., p. 606, que las equiparan con la regulación de los sistemas institucionales de protección (SIP) típico entre entidades de crédito. 
Para terminar una reflexión final. En 2016 habían en España inscritas en la Dirección General de Seguros 31 mutuas, que representan el apenas un 3\% del total de entidades del sector (1.091 entidades aseguradoras). En Europa, en cambio, las mutuas representan el $16 \%$ de la tasa de mercado. Estamos presenciando un proceso de desmutualización de algunas de las más importantes mutuas de nuestro país y, de las pocas novedades que contiene la nueva normativa de seguros privados se observa una tendencia a facilitar la transformación de mutuas en compañías de seguros o su absorción por estas. No parece que la constitución de grupos mutuales, con las exigencias de permanencia y cesión de derechos a la entidad matriz, vaya a ser una solución para la integración de mutuas en España. Habrá que esperar el contenido del esperado Reglamento de mutuas de seguros, pero poco va a cambiar las cosas porque las líneas maestras relativas a los procesos de reestructuración, modificaciones estructurales e integración, que son los aspectos básicos para evitar la desmutualización del sector y facilitar el crecimiento de las mutuas sin perder su identidad, ya están bien definidos en la normativa aprobada.

\section{Bibliografía}

Ávalos, L. M.: «Antecedentes históricos del mutualismo», CIRIEC-España, núm. 12, pp. 39-58.

BeníteZ de LUGo, L.: Tratado de seguros, vol. I, Madrid, 1955.

Bercovitz Rodríguez-Cano, A. y Broseta Pont, M.: «Mutuas de seguros, prima fija y carácter no mercantil», RDM, núms. 179-180, 1986, pp. 7-59.

Bercovitz Rodríguez-Cano, A. y Broseta Pont, M.: "Consideraciones sobre la naturaleza jurídica de las mutuas de seguros», RES, núm. 46, 1986, pp. 173186.

Carro del Castillo, J. A.: «Naturaleza jurídica de las mutuas de seguros», en Comentarios a la Ley de Ordenación del Seguro Privado, Dir. Verdera, vol. I, Madrid, 1988, pp. 423-443.

Caño Escudero, F.: Derecho español de seguros, T. I, Madrid, 1983.

Donatı, A.: Trattato del Diritto delle Assicurazioni Private, vol. I, Milán, 1952.

Duque Domínguez, F. J.: «Mutuas y cooperativas en la nueva legislación ordenadora del seguro privado», Comentarios a la Ley de Ordenación del Seguro Privado, Dir. Verdera, Madrid, 1988.

EMBID IRUJo, J.M.: «Problemas actuales de la integración cooperativa», RDM, núm. 227, pp. 7-36.

FajARDo García, G.: «Entidades mutualistas en el mercado asegurador», en Supervisión en seguros privados: Hacía solvencia II, Dir. Cuñat y Bataller, Valencia, 2013, pp. 503-540.

GARRIDO Y Comas, J. J: El mutualismo privado en la Europa del siglo XX, Mapfre, Madrid, 1992. 
GarRido y Comas, J. J.: Tratado general de seguros, t, I, vol. I, Madrid, 1986.

GARRIgues, J.: Contrato de seguro terrestre, Madrid, 1. a ed., 1973.

GIRGAdo PeRAndones, P.: «Una aproximación a la regulación de los grupos de entidades de seguros en la LOSSEAR», en Libro de Actas III Congreso Nacional de Ordenación, Solvencia y Supervisión en Seguros Privado, Dir. Bataller y Peñas, Valencia, 2016, pp. 531-554

GoldsCHMIDT, L.: Storia universale del diritto commerciale (trad. Pouchain y Scialoja de la original Universalgeschichte des Handelsrechts, Stuttgart, 1891), Torino, 1913

Herrmannsdorfer, F.: Seguros Privados, Madrid, 1933.

Llobregat HuRTADO, M. ${ }^{a}$ L.: Mutualidad y empresas cooperativas, Barcelona, 1991.

Maldonado Molina, F. J.: Aspectos societarios de las mutualidades, Madrid, Edersa, 2001.

Martínez Segovia, F. J.: «La relación cooperativizada entre la sociedad cooperativa y sus socios: naturaleza y régimen jurídico», RdS, núm. 25, pp. 203-234.

Moreno, R.: Mutualidades, Cooperativas, Seguro y Previsión Social, Madrid, CES, Madrid, 2000.

Moreno, R.: «La génesis del mutualismo moderno en Europa», REVESCO, núm. 72, pp. 199-214.

MORENO, R.: «Las empresas de participación aseguradoras y la concentración», REVESCO, núm. 73, 2001, pp. 81-94.

Paniagua Zurera, M.: Mutualidad y lucro en la sociedad cooperativa, Madrid, MacGraw-Hill, 1997.

PANiAgua Zurera, M.: La sociedad cooperativa. Las sociedades mutuas de seguros y las mutualidades de previsión social, vol. I, en Tratado de Derecho mercantil, Madrid, 2005.

Paniagua Zurera, M.: Las empresas de economía social, Madrid, 2011.

SÁnchez Calero, F.: Curso de Derecho del Seguro Privado, Bilbao, 1961.

San Pedro Martínez, G. y Vidal, P.: "Apuntes sobre los grupos mutuales en el Proyecto de Ley de Supervisión de los Seguros Privados», en Supervisión en Seguros Privados. Hacia solvencia II. Actas del Congreso de Ordenación y Supervisión en Seguros Privados. Valencia, 15 y 16 de septiembre de 2011, Cuñat Edo y Bataller Grau (Dirs.), Valencia, 2013, pp. 605-617.

TIRAdo SuÁrez, F. J.: Ley ordenadora del seguro privado: exposición y crítica, Sevilla, Universidad de Sevilla, 1984.

TIRADO SUÁREZ, F. J.: "La relación mutualista entre socio y cooperativa en el Derecho de seguros vigente», en Derecho de Sociedades. Libro homenaje a Fernando Sánchez Calero, t. V, Madrid, 2002, pp. 4481-4505.

Tirado SuÁrez, F.J. y Moreno Sanz, F.: «La Sociedad Mutua Europea», RES, núm. 22, 1980, pp. 121-155.

Tous Granda, E.: «La falta de la regulación de la mutua de seguros en la Ley 20/2015, de 14 de julio, de Ordenación, Supervisión y Solvencia de las entidades aseguradoras y reaseguradoras», en Libro de Actas III Congreso Nacional de Ordenación, Solvencia y Supervisión en Seguros Privado, Dir. Bataller y Peñas, Valencia, 2016, pp. 431-442. 
Vargas Vasserot, C.: «Las Mutuas de Seguros. Especial referencia a la doble condición de socio y asegurado del mutualista», en Supervisión en Seguros Privados. Hacia solvencia II. Actas del Congreso de Ordenación y Supervisión en Seguros Privados. Valencia, 15 y 16 de septiembre de 2011, Cuñat Edo y Bataller Grau (Dirs.), Valencia, 2013, pp. 577-587.

VARGAS VASSEROT, C.: La actividad cooperativizada y las relaciones de la cooperativa con sus socios y con terceros, Cizur Menor, Aranzadi, 2006.

VICENT CHULIÁ, F.: "Aspectos relevantes del régimen de las mutuas de seguros», en Estudios de Derecho Mercantil: homenaje al profesor Justino F. Duque, vol. I, Valladolid, UVA, 1998, pp. 729-750.

VICENT CHULIÁ, F.: «Aspectos relevantes del régimen jurídico de la mutua de seguros a prima fija», $R G D$, núms. 640-641, 1998, pp. 615-650.

VICENT CHULIÁ, F.: "Las empresas mutualísticas y el Derecho mercantil en el ordenamiento español», RCDI, núm. 512, 1976, pp. 69-134. 